\title{
Fish gut content from biological collections as a tool for long-term environmental impact studies
}

\author{
Pedro Sartori Manoel • Valter M. Azevedo-Santos
}

Received: 29 September 2017 / Accepted: 5 February 2018 /Published online: 16 February 2018

(C) Springer Science+Business Media B.V., part of Springer Nature 2018

\begin{abstract}
Most of the world's fish fauna is suffering from different types of human impacts and new conservation tools are required. The fish diet analysis is a tool that has been used to evaluate degradation processes of aquatic environments, however, few longterm studies are performed by several reasons (e.g., lack of funding, opportunity). Our aim was to test whether the fish gut content from biological collections can be used for comparisons with current data and, consequently, be used as a tool for long-term environmental impact studies. We compared the gut content of fish preserved for fifteen years in a biological collection with recently sampled fish, considering the factors size of the specimen, preservation time and preservation form. We did not find differences in the gut content percentage of preservation between fish size classes and preservation time. However, we found differences between preservation form, in which the fish fixed in formalin kept the digestive content preserved while the fish preserved directly in alcohol did not. Thus, we encourage the use of fish gut content from biological collections fixed in formalin for long-term ecological studies. Our findings may help elucidate some long-term effects of human impacts on fish fauna.
\end{abstract}

P. S. Manoel $(\bowtie) \cdot$ V. M. Azevedo-Santos

Departamento de Zoologia, Instituto de Biociências de Botucatu, Universidade Estadual Paulista (UNESP), São Paulo, Brazil e-mail: pedrosartori.bio@gmail.com
Keywords Diet · Fixation · Formalin · Icthyofauna . Stomach contents $\cdot$ Trophic ecology

\section{Introduction}

Global biodiversity is currently facing one of the largest existing crises (Singh 2002), where it is possible to observe a loss of a large number of species, including fish (Barletta et al. 2010). Several anthropogenic impacts have directly affected the ichthyofauna such as dam construction, fishing, water diversion projects, mining, introduction of non-native species, removal of riparian vegetation, and water contamination (e.g., domestic and industrial effluents, oil spills), among others (AzevedoSantos et al. 2016; Reis et al. 2016; Pelicice et al. 2017; Vitule et al. 2017). All these impacts have negative effects, and have been occurring with high frequency in several parts of the planet (e.g.,Winemiller et al. 2016; Pelicice et al. 2017). Thus, new and effective tools to detect and avoid these impacts are urgently needed (Stevenson and Woods 2006).

Dietary analysis has been used for decades in biology and ecology studies of different fish species (Baker et al. 2014) and in the evaluation of human impacts in aquatic environments. For instance, Tófoli et al. (2013) found a negative relation between the diversity of food items ingested by a fish species and the level of urbanization of streams in the Southern Brazil. In turn, Ferreira et al. (2015) observed that the edge effect resulting from forest fragmentation causes the substitution in the ingestion of vegetal debris and terrestrial insects by algae and organic 
matter in the fish assembly. Another example is the study of Zeni and Casatti (2014), that found a reduction of trophic guilds diversity in the streams fish assemblages that underwent habitat homogenization process caused mainly by the riparian vegetation removal. These studies indicate that environmental conditions influence the supply and selection of resources by fish species (Tófoli et al. 2013; Castro et al. 2016). However, most of these studies are about spatial changes or a short timeframe, and longterm studies (more than ten years) are rare in the scientific literature.

Biological collections of fish are present in many parts of the planet (see Sabaj-Péres 2014) and are very important for biological studies (Rocha et al. 2014), although they are often undervalued (Minteer et al. 2014). Biological samples from surveys and taxonomic or ecological studies are deposited in these collections (e.g., Casatti et al. 2015; Santos et al. 2017) and may also be useful for further studies. For example, Jaron Hill et al. (2010), showed that fish preserved in biological collections can be used to assess levels of fish contamination by mercury over time. In this context, we believe that biological collections should be used more often to acess environmental impacts. Gut content of fish specimens preserved, in particular, may provide information about the environment at the time the fish were sampled in the past, which can be compared with fish collected in the same environment in the present. Thus, our aim was to test whether the gut content of fish from biological collections can be used for comparisons with current data and, consequently, be used as a tool for long-term environmental impact studies.

\section{Material and methods}

In this study we used specimens of Astyanax cf. paranae (Characidae), a small fish widely distributed and abundant in small streams of southeastern Brazil (Bertaco and Lucena 2006). This species was chosen because it is omnivorous, and can eat a wide variety of food items, e.g., aquatic and terrestrial insects, plant material, organic matter and algae (Ferreira et al. 2012). Thus, with this species it would be possible to evaluate the degree of preservation of different alimentary items with varying decomposition times.

The study was carried out using A. cf. paranae specimens recently sampled in 2016 (Calmaria Stream, Paranapanema River Basin, Botucatu, SP, Brazil), fixed directly in $10 \%$ formalin for three days and later preserved in alcohol 70\% (2016-Formalin) and specimens from Coleção do Laboratório de Biologia e Genética de Peixes (LBP), Departamento de Morfologia, Universidade Estadual Paulista, Botucatu, SP, Brazil. We chose two lots of $A$. cf. paranae from this collection: LBP - 943 with specimens sampled in 2001, fixed in $10 \%$ formalin for three days and later preserved in alcohol 70\% (2001-Formalin); and LBP - 13,928, with specimens also sampled in 2001, but inserted directly into $70 \%$ alcohol (2001-Alcohol).

In this study, we considered three factors that could affect the preservation of fish gut contents: (i) size of the specimen, (ii) preservation time and (iii) preservation form. To test the size factor, we compared 10 specimens of three size classes (i.e., small SL $<20 \mathrm{~mm}$, average $\mathrm{SL}>20 \mathrm{~mm}<50 \mathrm{~mm}$ and large $\mathrm{SL}>50 \mathrm{~mm}$ ). For the factor preservation time, we compared the gut content of 2001-Formalin and 2016-Formalin, the two lots with fixation in formalin and preservation in alcohol. For the factor preservation form, we compared the gut content of the 2001-Formalin and 2001-Alcohol.

We assess the gut content of each fish by measuring the area of the food items presented in their stomach with a glass slide placed on a millimetric paper. We chose to use the food items area due to their small size and the impossibility of calculating their volume. We also quantified the frequency of occurrence of food items consumed by the fish analyzed, in order to verify if some type of item is better preserved in relation to another in the different groups.

As a way of measuring the degree of preservation of the digestive contents of the different sets of fish, we calculated for each specimen the gut content percentage of preservation, which is the ratio between the area of the preserved gut content and the area of total gut content. We classified as preserved gut content that portion for which it was possible to identify the food items, and total gut content the sum of the preserved gut content with the remains of material in the decomposition process that could not be identified.

For the data analysis, we first verify normality using the Shapiro-Wilk test and homoscedasticity using Levene's test. In order to verify the significant differences in the gut content percentage of preservation between the groups considering the factors size of the specimen, preservation time and preservation form, we created box-andwhisker plot graphs and we used one-way analysis of variance (ANOVA), with Tukey's tests a posteriori for parametric data and Kruskal-Wallis test, with Mann- 
Whitney tests a posteriori for nonparametric. For all the tests we assumed the significance value of $p<0.01$.

\section{Results}

We found five classes of food items in the analyzed fish gut contents (Table 1) that were in good state of preservation (Fig. 1). In all fish size class of 2001Formalin and 2016-Formalin we found the five classes of food items with a high frequency of occurrence of aquatic insects, vegetal debris and terrestrial insects followed by a low frequency of occurrence of filamentous algae and organic matter. While in the group of fish inserted directly into alcohol, we found only terrestrial insects fragments mixed with decomposing material that could not be identified.

For the fish size class factor (Fig. 2), the ANOVA did not show significant difference in the gut content percentage of preservation between the three size classes for the three sets of fish analyzed (i.e., 2001-Formalin $p=0.919,2001$-Alcohol $p=0.925,2016-$ Formalin $p=$ 0.856). For the preservation time factor (Fig. 3), the Mann-Whitney test comparing fish of 2001-Formalin and 2016-Formalin did not show significant difference in the gut content percentage of preservation between the years $(p=0.46)$. However, for the preservation form factor (Fig. 3), the Mann-Whitney test comparing fish of 2001 preserved in formalin and alcohol showed significant difference $(p<0.0001)$.

Table 1 Occurrence of food items found in the gut contents of specimens of Astyanax cf. paranae of the three studied groups

\begin{tabular}{|c|c|c|c|c|c|c|c|c|c|}
\hline & \multicolumn{3}{|c|}{$\begin{array}{l}2001- \\
\text { Formalin }\end{array}$} & \multicolumn{3}{|c|}{$\begin{array}{l}\text { 2001- } \\
\text { Alcohol }\end{array}$} & \multicolumn{3}{|c|}{$\begin{array}{l}2016- \\
\text { Formalin }\end{array}$} \\
\hline & $\mathrm{S}$ & M & $\mathrm{L}$ & $\mathrm{S}$ & M & $\mathrm{L}$ & $\mathrm{S}$ & M & $\mathrm{L}$ \\
\hline Algae & 2 & 1 & 1 & 0 & 0 & 0 & 1 & 1 & 1 \\
\hline Aquatic insects & 9 & 8 & 9 & 0 & 0 & 0 & 10 & 8 & 8 \\
\hline Terrestrial insects & 2 & 3 & 4 & 5 & 4 & 6 & 1 & 5 & 7 \\
\hline Vegetal debris & 6 & 10 & 9 & 0 & 0 & 0 & 4 & 5 & 9 \\
\hline Organic matter & 1 & 1 & 2 & 0 & 0 & 0 & 1 & 1 & 1 \\
\hline
\end{tabular}

2001-Formalin=Fish sampled in 2001 fixed in formalin and preserved in alcohol; 2001-Alcohol = fish sampled in 2001 and preserved directly in alcohol and 2016-Formalin = fish sampled in 2016 fixed in formalin and preserved in alcohol. Sample size for each size class $=10$ specimens. $S$ Small, $M$ Medium, $L$ Large
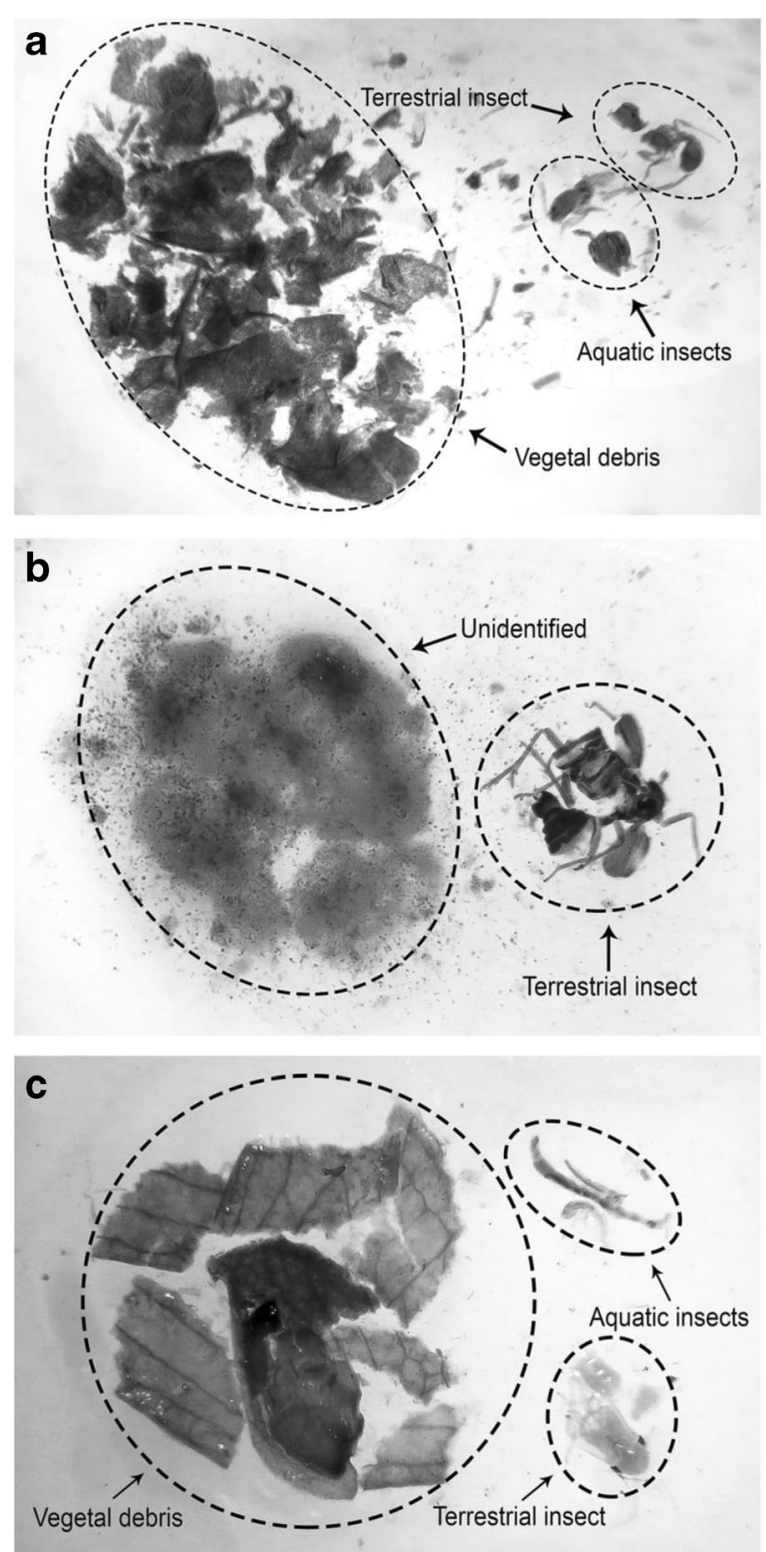

Fig. 1 Examples of Astyanax cf. paranae gut content from individuals belonging to the groups (a) 2001-Formalin - Fish sampled in 2001 fixed in formalin and preserved in alcohol; (b) 2001-Alcohol = fish sampled in 2001 and preserved directly in alcohol; (c) 2016-Formalin = fish sampled in 2016 fixed in formalin and preserved in alcohol

\section{Discussion}

Based on our results, we found that the digestive contents preservation is independent of the size of the specimen. Although we used only one fish species that does not reach large sizes (Maximum length $=11.3 \mathrm{~mm}$; Alcaraz et al. 2009), we believe that in species that reach 

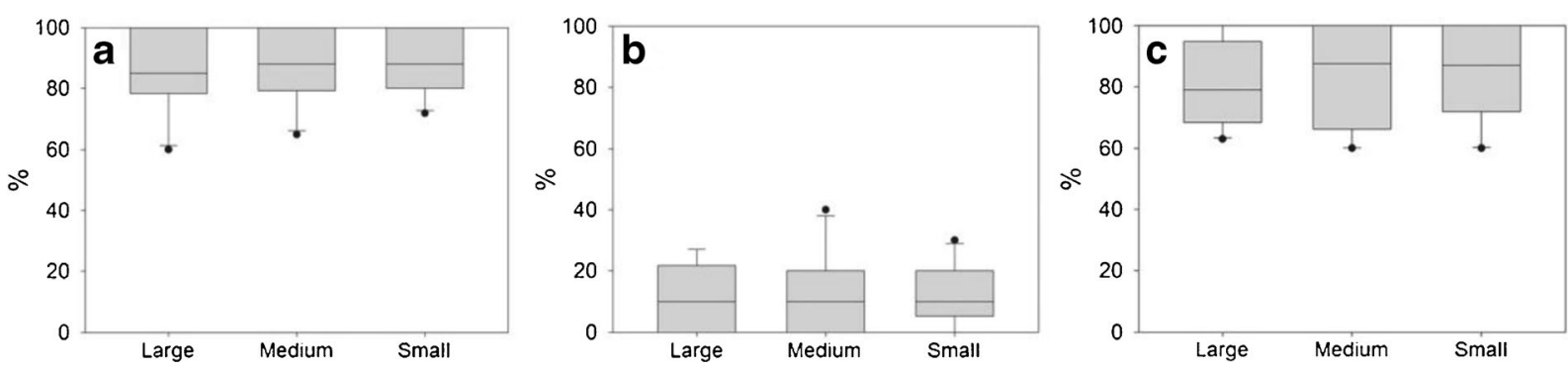

Fig. 2 Box-and-Whisker plots showing the gut content percentage of preservation in the different sizes of Astyanax cf. paranae in the groups: (a) 2001-Formalin - Fish sampled in 2001 fixed in formalin and preserved in alcohol; (b) 2001-Alcohol = fish

larger sizes the inoculation of formalin in the digestive cavity is sufficient for the gut content fixation. In addition, this approach may detect ontogenetic feeding modifications, which are a pattern in several fish species (Balon 1986), that can be caused by anthropogenic impacts and affect individuals of different species in different growth stages (Wolff et al. 2009).

As we showed, fish fixed in formalin after 15 years kept the gut content preserved, which is possible to identify the food items ingested. Since impacts on the ichthyofauna have been frequent, sometimes unpredictable, and with tendencies to intensify all over the planet (e.g., Pelicice et al. 2017), we believe that an 15 years interval is sufficient for conducting longterm anthropogenic impacts studies. In addition, we believe that species that have been fixed directly in formalin and adequately preserved in biological collections for more than 15 years (time used in this study) may also have the gut content preserved and compared with recent material.

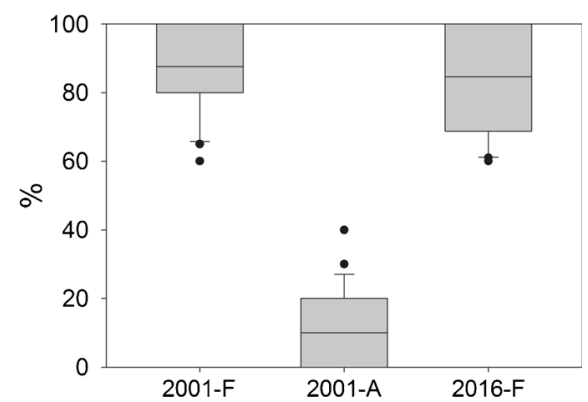

Fig. 3 Box-and-Whisker plots showing the gut content percentage of conservation in the different groups of Astyanax cf. paranae in the groups: 2001-Formalin - Fish sampled in 2001 fixed in formalin and preserved in alcohol; 2001-Alcohol = fish sampled in 2001 and preserved directly in alcohol; 2016-Formalin = fish sampled in 2016 fixed in formalin and preserved in alcohol. Sample size for each size class $=30$ specimens sampled in 2001 and preserved directly in alcohol; (c) 2016Formalin $=$ fish sampled in 2016 fixed in formalin and preserved in alcohol

In their study, Buckland et al. 2017 discusses some of the challenges facing long-term diet studies and the importance of considering gut content condition. According to them, the use of historical data may be compromised by their lack of standardization and information about the gut content condition, which often precludes the feasibility of long-term studies on fish diet. Thus, the gut content of fish from biological collections may be an alternative to these difficulties, since we demonstrated that, when properly fixed, the digestive content remains preserved in good conditions and there is a greater facility in the standardization of methods since the same researcher can choose them.

The presence of food items with different origins and characteristics such as insects, vegetal debris, organic matter and filamentous algae in the gut contents of the specimens in the two groups fixed in formalin confirms our hypothesis that fish from biological collections, when properly fixed, keeps the gut content in good condition of identification. The differences found in the frequency of occurrence of these food items are probably due to the stream resources supply and fish individual choice rather than the preservation capacity of each item, since the consumption of these food items were similar to other studies with A. paranae (e.g., Rolla et al. 2009; Ferreira et al. 2012). Therefore, our findings suggest that if dietary composition changes over time, it could be detected in the carefully preserved specimens.

The difference in the results obtained for the preservation form shows the importance of a good biological material fixation to incorporate it into biological collections. In our study, we observed only terrestrial insects in the gut content of fish preserved directly in the alcoeton exclerotization of these insects (Borror et al. 1989), hol and this probably occurred due to the high exoskel- 
which may delay its decomposition. This can cause nonreal results related to fish diet, since they can feed on a high diversity of food items, but only terrestrial insects are found. Thus, we indicate that for diet analysis the researcher, as soon as they collect the fish, fix them directly in formalin for at least $24 \mathrm{~h}$, and then transfer them to alcohol. We suggest the use of $10 \%$ formalin and $70 \%$ alcohol as verified in this study.

Although we have used only one species of freshwater fish in this study, we believe this tool can also be used with marine fish, since estuarine environments also suffer from a large number of anthropogenic impacts (Nagelkerken et al. 2015). In addition, we suggest testing this tool on other vertebrate groups that are fixed in liquid substance (e.g., amphibians and reptiles), since these animals are also highly susceptible to anthropogenic impacts (Gillespie et al. 2015).

According to our results, we encourage the implementation of fish fauna scientific surveys, especially in places that are subject to future anthropogenic impacts, such as hydroelectric dams, urban areas expansion and deforestation for agricultural production. We emphasize the importance of a good fixation of this material at the sampling time and its deposit in biological collections, as it may be useful for future studies. However, in environments with low populations or high endemism, we do not recommend such sampling. According to Abilhoa et al. (2011), for these environments, nonlethal methods of stomach contents analysis should be used, such as gastric lavage (Braga et al. 2017).

\section{Conclusions}

Fish from biological collections can be used in diet studies of freshwater fish. Therefore, they can also be compared with current data to obtain results of environmental changes over time in aquatic environments, especially those that were targeted by anthropogenic impacts. However, it is necessary for these fish to be fixed directly into formalin and subsequently transferred to alcohol. This is undoubtedly a way of retrieving data of the environment in which the fish fauna resided in the past and subsidize restoration and conservation measures in impacted areas.

Acknowledgements Our thanks to Ronald Baker, Fernando M. Pelicice and Virginia S. Uieda for reviewing our manuscript and collaborating with their corrections and suggestions. This research did not receive any specific grant from funding agencies in the public, commercial, or not-for-profit sectors. The 2016 specimens were collected in accordance to Brazilian Institute of Environment and Renewable Natural Resources (IBAMA) and Sistema de Autorização e Informacão em Biodiversidade (SISBIO) permit number: 52777-1.

\section{References}

Abilhoa V, Braga RR, Bornatowski H, Vitule JRS (2011) Fishes of the Atlantic rain forest streams: ecological patterns and conservation. In: Grillo $\mathrm{O}$ (ed) Changing diversity in changing environment. InTech, Rijeka, pp 259-282

Alcaraz HSV, Pavanelli CS, Bertaco VA (2009) Astyanax jordanensis (Ostariophysi: Characidae), a new species from the rio Iguaçu basin, Paraná, Brazil. Neotrop Ichthyol 7:185190. https://doi.org/10.1590/S1679-62252009000200008

Azevedo-Santos VM, Garcia-Ayala JR, Fearnside PM et al (2016) Amazon aquatic biodiversity imperiled by oil spills. Biodivers Conserv 25(13):2831-2834. https://doi. org/10.1007/s10531-016-1192-9

Baker R, Buckland A, Sheaves M (2014) Fish gut content analysis: robust measures of diet composition. Fish Fish 15:170 177. https://doi.org/10.1111/faf.12026

Balon EK (1986) Types of feeding in the ontogeny of fishes and the life-history model. Environ Biol Fish 16:11-24

Barletta M, Jaureguizar AJ, Baigun C, et al (2010) Fish and aquatic habitat conservation in South America: a continental overview with emphasis on neotropical systems. J Fish Biol 76:2118-2176. https://doi.org/10.1111/j.10958649.2010.02684.x

Bertaco VA, Lucena CAS (2006) Two new species of Astyanax (Ostariophysi: Characiformes: Characidae) from eastern Brazil, with a synopsis of the Astyanax scabripinnis species complex. Neotrop Ichthyol 4:53-60. https://doi. org/10.1590/S1679-62252006000100004

Borror DJ, Triplehorn CA, Johnson NF (1989) An introduction to the study of insects. Saunders College Publishing, Philadelphia

Braga RR, Ribeiro V, Bornatowski H et al (2017) Gastric lavage for dietary studies of small fishes: Efficiency, survival and applicability. Acta Ichthyol Piscat 47:97-100. https://doi. org/10.3750/AIEP/02079

Buckland A, Baker R, Loneragan N, Sheaves M (2017) Standardising fish stomach content analysis: The importance of prey condition. Fish Res 196:126-140. https://doi. org/10.1016/j.fishres.2017.08.003

Casatti L, Teresa FB, Zeni JO et al (2015) More of the Same: High Functional Redundancy in Stream Fish Assemblages from Tropical Agroecosystems. Environ Manag 55:1300-1314. https://doi.org/10.1007/s00267-015-0461-9

Castro DMP, Carvalho DR, Pompeu PS et al (2016) Land Use Influences Niche Size and the Assimilation of Resources by Benthic Macroinvertebrates in Tropical Headwater Streams. PLoS One 11:e0150527. https://doi.org/10.1371/journal. pone. 0150527 
Ferreira A, de Paula FR, Ferraz SFB et al (2012) Riparian coverage affects diets of characids in neotropical streams. Ecol Freshw Fish 21:12-22. https://doi.org/10.1111/j.16000633.2011.00518.x

Ferreira CP, Casatti L, Zeni JO, Ceneviva-Bastos M (2015) Edgemediated effects of forest fragments on the trophic structure of stream fish. Hydrobiologia 762:15-28. https://doi. org/10.1007/s10750-015-2330-1

Gillespie GR, Howard S, Stroud JT et al (2015) Responses of tropical forest herpetofauna to moderate anthropogenic disturbance and effects of natural habitat variation in Sulawesi, Indonesia. Biol Conserv 192:161-173. https://doi. org/10.1016/j.biocon.2015.08.034

Jaron Hill J, Chumchal MM, Drenner RW et al (2010) Use of preserved museum fish to evaluate historical and current mercury contamination in fish from two rivers in Oklahoma, USA. Environ Monit Assess 161:509-516. https://doi.org/10.1007/s10661-009-0764-5

Minteer BA, Collins JP, Love KE, Puschendorf R (2014) Avoiding (Re)extinction. Science 344:260-261. https://doi. org/10.1126/science. 1250953

Nagelkerken I, Sheaves M, Baker R, Connolly RM (2015) The seascape nursery: a novel spatial approach to identify and manage nurseries for coastal marine fauna. Fish Fish 16:362371. https://doi.org/10.1111/faf.12057

Pelicice FM, Azevedo-Santos VM, Vitule JRS et al (2017) Neotropical freshwater fishes imperilled by unsustainable policies. Fish Fish:1-15. https://doi.org/10.1111/faf.12228

Reis RE, Albert JS, Di Dario F et al (2016) Fish biodiversity and conservation in South America. J Fish Biol 89:12-47. https://doi.org/10.1111/jfb.13016

Rocha LA, Aleixo A, Allen G et al (2014) Specimen collection: An essential tool. Science 344:814-815. https://doi. org/10.1126/science.344.6186.814

Rolla APPR, Esteves KE, Ávila-da-Silva AO (2009) Feeding ecology of a stream fish assemblage in an Atlantic Forest remnant (Serra do Japi, SP, Brazil). Neotrop Ichthyol 7:6576. https://doi.org/10.1590/S1679-62252009000100009
Sabaj-Péres MH (2014) Standard symbolic codes for institutional resource collections in herpetology and ichthyology: an Online Reference. Version 5.0 (22 September 2014). Electronically accessible at http://www.asih.org/. In: Am. Soc. Ichthyol. Herpetol. Whashington, DC

Santos AC, Gonçalves CC, Carvalho FR (2017) Ichthyofauna of the "Cachoeira de São Roberto" and fishes of lower Preto River, upper Paraná River basin, Brazil. Biota Neotrop 17:110. https://doi.org/10.1590/1676-0611-bn-2016-0196

Singh JS (2002) The biodiversity crisis: A multifaceted review. Curr Sci 82:638-647

Stevenson RD, Woods WA (2006) Condition indices for conservation: new uses for evolving tools. Integr Comp Biol 46: 1169-1190. https://doi.org/10.1093/icb/icl052

Tófoli RM, Alves GHZ, Higuti J et al (2013) Diet and feeding selectivity of a benthivorous fish in streams: responses to the effects of urbanization. J Fish Biol 83:39-51. https://doi. org/10.1111/jfb. 12145

Vitule JRS, Agostinho AA, Azevedo-Santos VM et al (2017) We need better understanding about functional diversity and vulnerability of tropical freshwater fishes. Biodivers Conserv 26:757-762. https://doi.org/10.1007/s10531-0161258-8

Winemiller KO, McIntyre PB, Castello L et al (2016) Balancing hydropower and biodiversity in the Amazon, Congo, and Mekong. Science (80- ) 351:128-129. https://doi. org/10.1126/science.aac7082

Wolff LL, Abilhoa V, Rios FS, Donatti L (2009) Spatial, seasonal and ontogenetic variation in the diet of Astyanax aff. fasciatus (Ostariophysi: Characidae) in an Atlantic Forest river, Southern Brazil. Neotrop Ichthyol 7:257-266. https://doi.org/10.1590/S1679-62252009000200018

Zeni JO, Casatti L (2014) The influence of habitat homogenization on the trophic structure of fish fauna in tropical streams. Hydrobiologia 726:259-270. https://doi. org/10.1007/s10750-013-1772-6 